\title{
OPHTHALMOLOGY AT THE AUSTRALIAN MEDICAL CONGRESS
}

\begin{abstract}
$-$
The Australian Medical Congress was held in the buildings of the University of Melbourne from November 12 to 17, 1923. The President of the Onhthalmological Section was Dr. Paton of Perth, who, in the course of a very interesting presidential address gave first-hand practical information on the intra-muscular use of milk in the treatment of trachoma. The proceedings of the Section included a discussion on the treatment of trachoma, in which a number of members deprecated the excision of the tarsus on the ground that it does not prevent recurrence in many cases, and it renders subsequent treatment exceedingly difficult.

Dr. Lockhart Gibson of Brisbane, drew attention to the danger run by the assumption that a negative Wassermann reaction excludes syphilis, and illustrated his thesis.

Dr. Leonard Mitchell presented the result of a clinical study of 110 cases of renal disease and arterio-sclerosis. The general opinion of members was that the so-called albuminuric retinitis was a symptom of extreme gravity when white effusion made its appearance, that haemorrhages were of very little serious significance, and that albuminuric retinitis without high blood pressure was uncommon.
\end{abstract}

An elaborate analysis from the hereditary point of view of perinuclear cataract was furnished by Dr. J. Kingland Anderson. The hereditary nature of the condition was made fairly obvious.

Sir James Barrett produced some cases of accidents at sea, which may have been caused by defective vision. They were cases, notes of which were posted to the late Edward Nettleship from Australia, but reached London after his death, and are now on record. He also urged the appointment of schools for myopes and emphasized the importance of the work begun by Dr. Ernest Maddox of Bournemouth. As oculist to the Royal Victorian Institute for the Blind he furnished an analysis of all the cases which had entered that Institute for the last 20 years, and showed that at least half of the cases of blindness in children were due to venereal disease.

Dr. Newman dealt with the causation of myopia from the point of view of the failure of the membrane of Bruch, and Dr. Temple Smith gave an elaborate exposition of his method of rectifying strabismus.

The papers will appear in full in the Australian Medical Journal. An excellent clinical demonstration was given at the Eye and Ear Hospital, Melbourne, on the afternoon of Tuesday, November 13. 